\title{
Characterization of Poly(vinyl chloride). IV. Porosity in PVC Powder Samples
}

\author{
Richard K.S. CHAN and John BEALE \\ Polymer Research, \\ Air Products and Chemicals, Inc. \\ Trexlertown, Pennsylvania 18105, U.S.A.
}

(Received December 15, 1971)

\begin{abstract}
Electron-microscopy and mercury intrusion porosimetry are employed to describe the porosity distribution in PVC particles from solution, bulk, emulsion, and suspension polymerizations. The results from both techniques are consistant. The interpretation of porosimetric data reveals the percentage of interparticle porosity, accessible and inaccessible intraparticle porosities of a powder sample.
\end{abstract}

KEY WORDS Porosity / Poly(vinyl chloride) / Porosimetry / Electron Microscopy / Intraparticle Porosity / Interparticle Porosity /

The porosity of poly(vinyl chloride) (PVC) plays an important role in the fusability and extrudate homogeneity of PVC products. Engle's work ${ }^{1}$ offers a brief review of work prior to 1962 . More recent work in this field includes references 2, 3, and 4. Most of these studies are aimed at presenting methods for porosity determination, correlation of porosity with processing/plasticizer adsorption and predicting the mechanism of particle formation. The methods of densities have been extensively covered. ${ }^{2}$ Our work is intended to provide better interpretation and correlation of the methods of electron microscopy and mercury porosimetry.

\section{POROSITY OF PVC PARTICLES PRODUCED FROM DIFFERENT COMMERCIAL PROCESSES AS REVEALED BY ELECTRON MICROSCOPY}

In the following, only transmission electron microscopy using microtomed section of the particle, is mentioned. Scanning electron microscopy can supplementarily reveal information about the morphology of particle surface, and it should not be overlooked eventhough it is not discussed in this paper.

\section{Porosity of PVC Solution Resins}

Since there are few good solvents for homopolymer of vinyl chloride, the final stage of many solution polymerizations changes from "homo- geneous" to "heterogeneous". When a poor solvent is used, the change takes place at lower conversion. Because particles precipitated are in swollen form, porosity distribution is believed to depend upon drying conditions, amount of swollen solvent and particle size. If particles are small (about $100 \mu$ ), porosity distribution appears

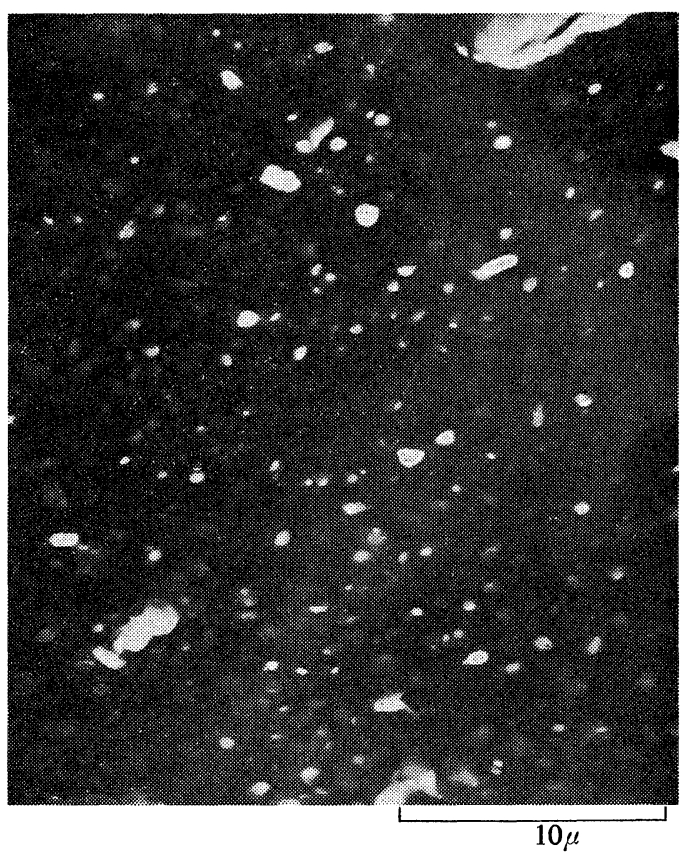

EM \#1. Intraparticle pore distribution of solution resin at $2200 \times$. 
to be very uniform in size throughout the whole parlicle, its porosity distribution is similar to that of foam (see the attached electron micrograph $\# 1$-the porosity distribution of a commercial resin made by solution polymerizations).

\section{Porosity of Bulk Resins}

The bulk process is briefly described in Pechiney Saint-Gobain's reference bulletin, U.S. Patent 3522227 ref 2. The French workers claimed that their bulk resins are much more porous than normal suspension resins and do not have a

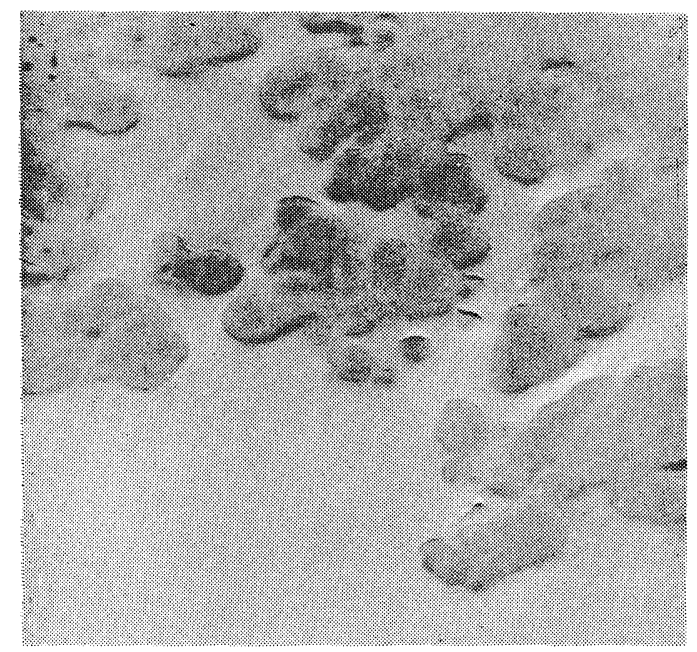

EM \#2. Intraparticle porosity of the porous particles in the PVC bulk resin, Lucovyl at $2833 \times$.

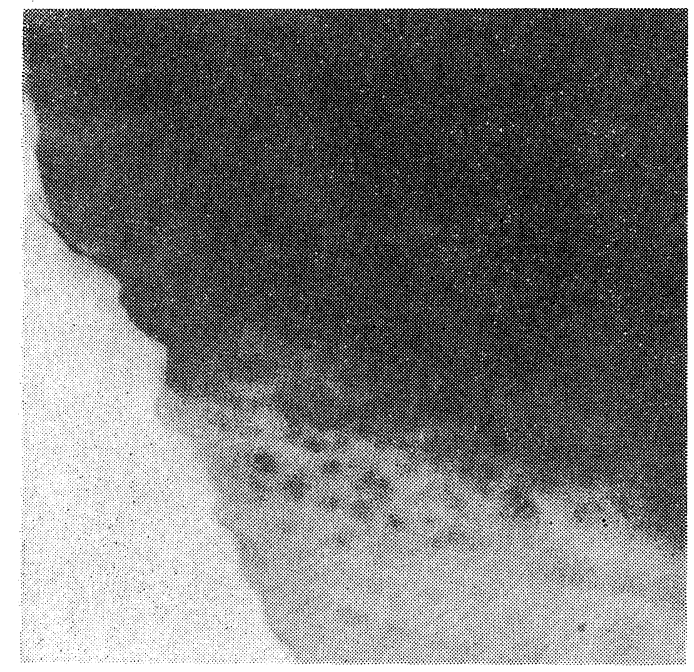

EM \#3. Porosity in the solid particles in bulk resins $(2833 \times)$. pericellular skin. These statements are born out by the attached electron micrograph $\# 2$. Our electron-microscopic studies revealed that in the French product 30 to $50 \%$ of the particles are essentially solid (see EM \#3). Heterogeneity in porosity in powder samples may damage their fusion properties. Judging from the size of voids in the porous particles, the porosity is believed to be reasonably open. The intraparticle porosity of the bulk products range from 0.12 to $0.233(\mathrm{cc} / \mathrm{gm})$ as determined by porosimetry described in the next section. The porosity in this kind of resin is believed to be controlled by percent conversion and by the shear field imposed by agitation in the reactor, which affects the agglommeration of precipitated polymer particles in the monomer during the polymerization process. $^{3}$ Very tight packing of these granules will produce almost solid particles; on the other hand, loose packing will give porous particles.

\section{Porosity of Emulsion Resins}

Because the density of $\mathrm{VCl}$ monomer is one third lower than that of its polymer; when $\mathrm{VCl}$ is polymerized, porosity may be developed in the emulsified swollen particles if the particle size stays constant. However, emulsion particles are of microsize (about $1 \mu$ ); shrinking of particle volume to minimize formation of new surface is more likely in small particles; therefore, a denser particle is expected from emulsion polymerization. Moreover, the number of free radicals in an emulsion particle is much less than that in a suspension droplet. Since PVC molecular weight does not vary with polymerization time, chain transfer to the nearest neighbor monomer is believed to be the primary mechanism for converting free radicals to the corresponding polymer molecules; this together with the restriction from small volume of emulsion particles would give a very dense particle as shown in Photo $\# 4$. Some particles appear to have a core and shell structure where the shell has a lower density than the core. The core and shell structure coincides with Williams' idea of particle structure in emulsion polymerization. (Presented in the Course "Emulsion Polymerization and Latex Technology", offered at Lehig University, June 1-5, 1970). The core and shell structure is believed to be an important factor in connection 


\section{R. K. S. Chan and J. Beale}

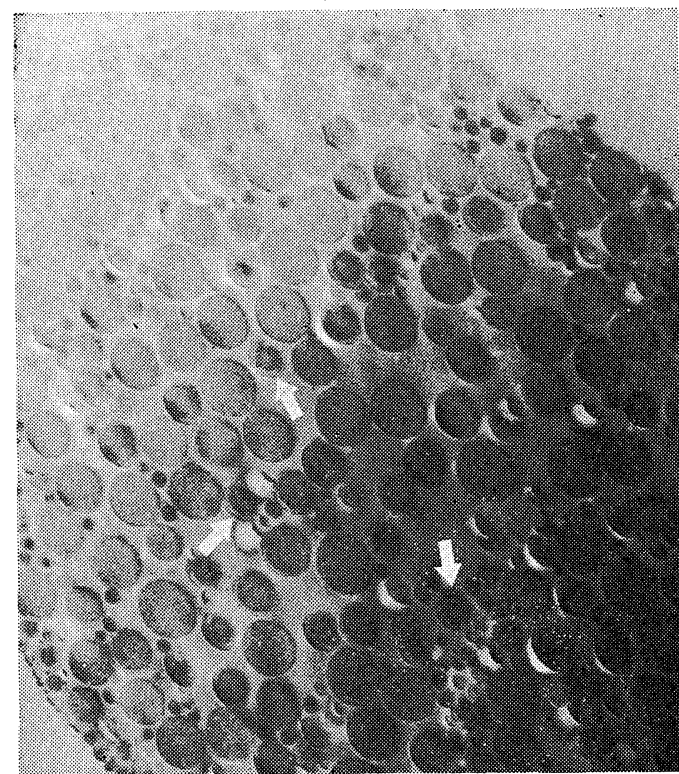

EM \#4. Core and shell structure of PVC emulsion particles at $10000 \times$ (from emulsion resin D61 of Fosfatbolaget).

with the fusion properties of these resins.

\section{Porosity of Regular Suspension Particles}

Electron micrograph $\$ 5$ depicts the porosity in normal suspension resin in which only the center

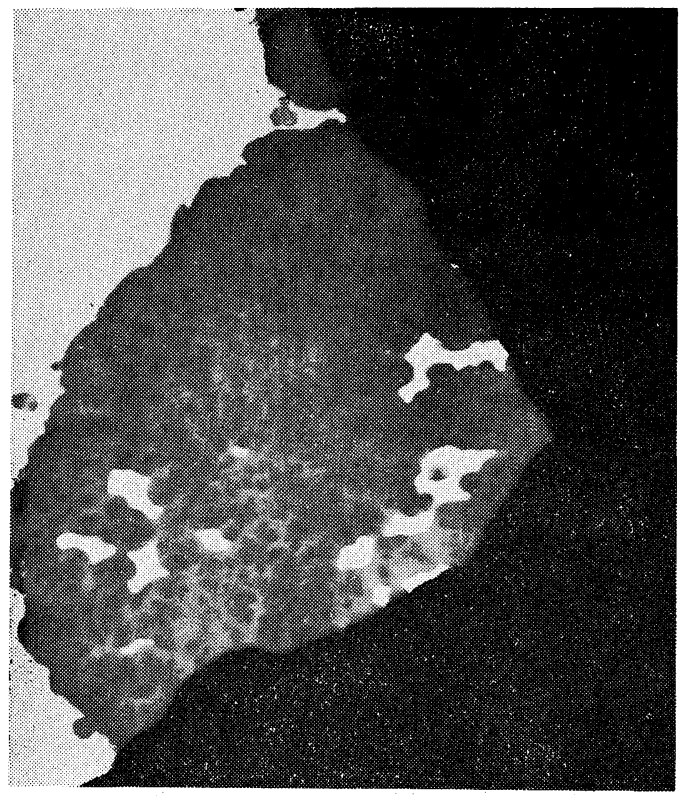

EM $\# 5$. Edge and intraparticle porosity of regular PVC suspension resin at $2200 \times$. portion appears to be porous. The picture also implies that the solid region results from agglommeration of precipitated particles inside the suspended monomer droplet. Regular suspension resins are not as porous as bulk resins because the precipitated particles inside the monomer droplets cannot attain as high degree of shear stabilization as those in bulk polymerization. Some suspension resins of copolymer, vinyl chloride/vinyl acetate, have a solid center and a porous shell, in contrast to regular suspension resins which have porous center (see attached electron micrograph $\# 6$ ).

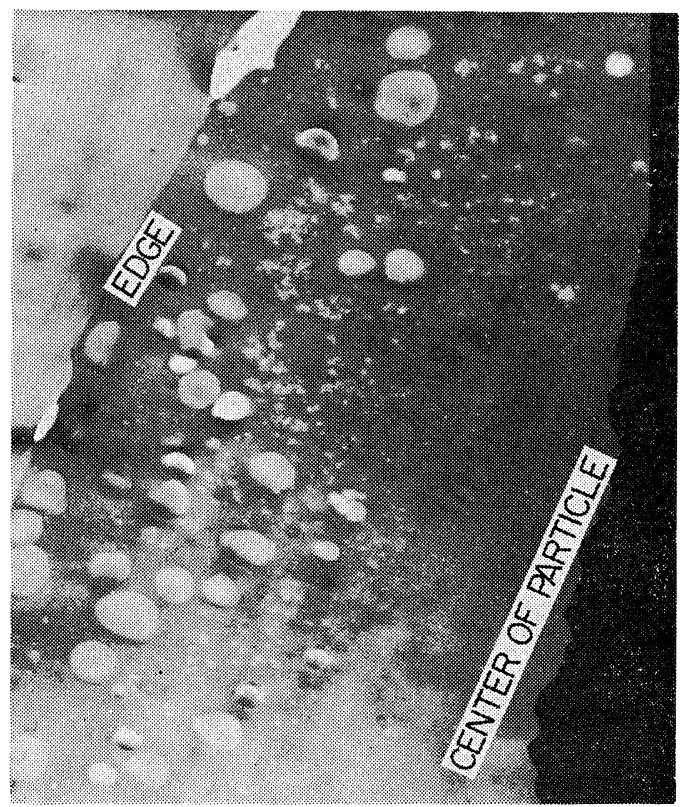

EM \#6. The intraparticle porosity of suspension resin of VCl-VA ccopolymer at $2200 \times$ (showing that the particle has a solid center.

\section{Porosity of PVC Pearls ${ }^{\mathrm{R}}$}

There is a special type of suspension resin, called PVC Pearls produced by Air Products and Chemicals, Inc. Sectioning electron-micrograph \#7 shows that this kind of resin has a distribution of pore size ranging from 0.2 to as high as $9 \mu$. The average pore size is about $1.5 \mu$ which is in accord with porosimetric findings to be described later. The pore size is isotropic in the radial direction. The intraparticle porosity of one resin was found by porosimetry to be about $26 \%$. The particles have essentially no pericellular 


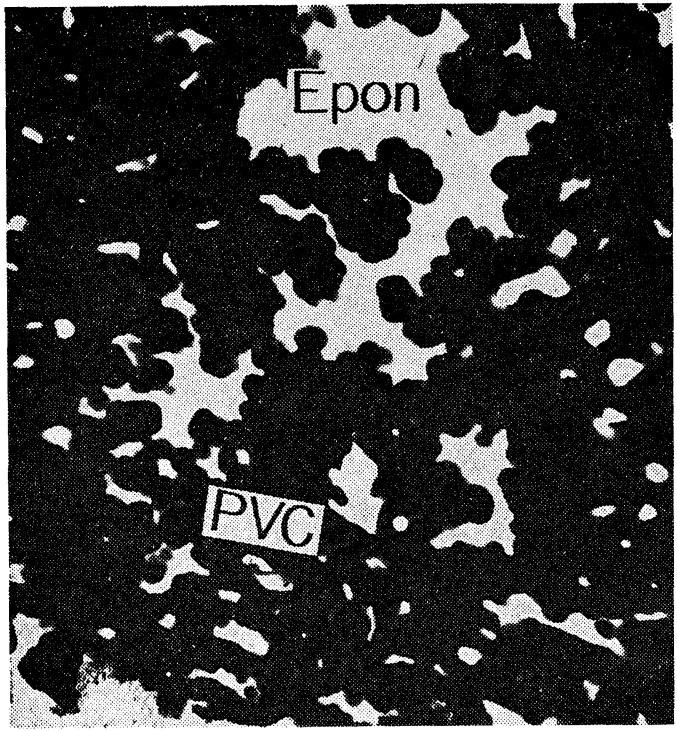

EM \#7. Edge and intraparticle Porosity of a special type of suspension resin, PVC Pearl resin from Escambia at $2200 \times$, showing Oper porosity, No pericellular membrane and uniform distribution of voids throughout the particle.

membrane. Judging from the pore size, it is believed that homopolymer PVC Pearls ${ }^{\mathrm{R}}$ have very small amount of large inaccessible voids. As a result, this kind of resin has good fusion properties. $^{5}$

\section{Quantitative Results from Electronmicroscopy}

Scanning electron microscopy is the best method for depicting the surface ruggedness; it also gives a qualitative idea of whether the surface porosity is open or closed. Transmission electron microscopy can give qualitative ideas about the degree and isotropy of porosity in the particle, heterogeneity of pore size, surface ruggedness and nature of porosity (whether it is open or closed). Quantitatively, it gives the average size of the intraparticle pores and the percentage of intraparticle void volume, $V_{\text {intra. }}$. Our method of obtaining the latter is as follows:

1. At least ten particles of different sizes were taken from a sample and embedded in an Epon resin, then cured for two days.

2. Microtome the center section of $1000-\AA$ thick from the embedded particles and examine the porosity distribution with respect to particle size under electron-microscope.

3. Select minimum representative sections for photographic recording. Usually four to eight sections are enough to represent the entire sample.

4. Take three pictures, one in the center and two at the edges of the selected sections.

About thirty electron-micrographs from the above procedure will be sufficient to describe the surface porosity and void distribution inside the particles. The percentage of void volume inside the particle, $V_{\text {intra }}$ can be obtained by photocopying the micrographs from sections, then, the "void" areas, $A_{\text {void }}$, which are occupied by Epon, are cut from the section. If $A_{\text {total }}$ denotes the total area of the section, (Epon area plus polymer area), then,

$$
V_{\text {intra }}=\frac{A_{\text {void }}}{A_{\text {total }}} \times 100, \%
$$

Note that $V_{\text {intra }}$ includes both the accessible and inaccessible intraparticle void volumes which have a pore size greater than $0.1 \mu$. Pores smaller than $0.1 \mu$ in size, are too small to "cut" and, thus, are not included. Table I lists the value of $V_{\text {intra }}$ of the micrographs from sections

Table I. Void volume of PVC pearls ${ }^{\mathrm{R}}$ from electron microscopy in $\%$

\begin{tabular}{|c|c|c|c|c|c|c|}
\hline \multirow[b]{2}{*}{$\begin{array}{l}\text { Distance } \\
\text { cut in, }\end{array}$} & \multicolumn{3}{|c|}{ Particle A, (135 diameter) } & \multicolumn{3}{|c|}{ Particle B, (200) } \\
\hline & $\begin{array}{l}V_{\text {intra }} \text { at left } \\
\text { edge of the } \\
\text { section }\end{array}$ & $\begin{array}{l}V_{\text {intra }} \text { at } \\
\text { center of the } \\
\text { section }\end{array}$ & $\begin{array}{l}V_{\text {intra }} \text { at right } \\
\text { edge of the } \\
\text { section }\end{array}$ & $\begin{array}{l}V_{\text {intra }} \text { at left } \\
\text { edge of the } \\
\text { section }\end{array}$ & $\begin{array}{l}V_{\text {intra at }} \\
\text { center of the } \\
\text { section }\end{array}$ & $\begin{array}{l}V_{\text {intra }} \text { at right } \\
\text { edge of the } \\
\text { section }\end{array}$ \\
\hline 5000 & - & 25 & - & - & - & - \\
\hline 15 & 28 & 29 & 31 & - & - & - \\
\hline 30 & 34 & 26 & 32 & 24 & - & - \\
\hline 50 & 30 & 24 & 39 & 16 & 28 & 22 \\
\hline 75 & - & - & - & 56 & 26 & 19 \\
\hline 100 & - & - & - & 27 & 27 & 18 \\
\hline
\end{tabular}


microtomed at different levels in two particles of a pearl resin. Examining the porosity of the micrograph at the edge of the section will reveal surface porosity or the existence of a pericellular membrane. Studying the porosity of pictures taken at the edge-center-edge of a section will give ideas about porosity distribution, (the anisotropy of pore size and $\%$ porosity) along the angular and radial directions. Comparing the porosity calculated from different particle size will disclose a qualitative idea about the relations of porosity distribution vs. particle size. For example, our electron microscopic studies of suspension PVC Pearls ${ }^{\mathrm{R}}$, revealed that such resin has a negligible pericellular membrane, and an average pore size at about $1.5 \mu$. Its distribution in pore size has essentially no preference in particle size, nor is the pore size anisotropic in both the angular and radial directions. The average $V_{\text {intra }}$ of this resin, calculated from eq 1 is about $29 \%$ from two large particles (about $200 \mu$ ) and $25 \%$ from two small particles (about $70 \mu)$.

\section{POROSITY STUDIES BY MERCURY POROSIMETRY}

This technique can be utilized to determine the percentage of interparticle porosity, accessible, and inaccessible intraparticle porosities and accessible pore size distribution inside the particles. The principle and procedure of mercury porosimetry are well described in the instruction manual of Aminco-Winslow Porosimeter, cat. No. 5-7106. A few problems need to be clarified before presenting the results generated from this technique.

1. What is the pressure (or equivalent pore size) at which the compressibility of PVC becomes important? From the porosimetric curve of a compression molded piece of $\mathrm{PVC}$, it was found that at a pressure of 500 psi (or equivalent pore size of 0.3 ) the compressibility of PVC must be considered. In other words, for porosity studies of PVC particles, pores of the size less than $0.3 \mu$ cannot be directly measured unless the compressibility of the polymer is isolated.

2. Would the particles float to the top of the intruded mercury inside the penetrometer chamber? If they do, the interparticle porosity, $\boldsymbol{P}_{\text {inter }}$ in $\mathrm{cc} / \mathrm{gm}$, so determined would be difficult to correlate. Careful observation of the intrusion process reveals that the bulk of the sample does not float and only a few particles float on top of the intruded mercury. The number of the floating particles is too small to affect any of the conclusions drawn in later parts of this paper. This contention is supported by the highly reproducible values of $\boldsymbol{P}_{\mathrm{inter}}$ at varying levels of the starting pressure used in filling the penetrometer (see Table II). For this reason floatation of particles during mercury intrusion is believed to be negligible.

3. Would the particles repack during the mercury intrusion process? The repacking of particles could arise from the redistribution of electrostatic charges between particles or from some unknown reasons. This question remains unresolved. If the porosimetric method should fail, this would most likely be the reason.

4. How should the accessible intraparticle porosity, $\boldsymbol{P}_{\text {acc }}$ in cc/gm and the inaccessible intraparticle porosity, $P_{\text {inace }}$ in $\mathrm{cc} / \mathrm{gm}$, be defined? In order to avoid the complications involved in assessing the compressibility of the polymer and rupture of the cell walls between pores at high pressure, it is decided to define $P_{\text {ace }}$ as the portion of specific intraparticle void volume which has pore size down to $0.3 \mu$, or is accessible to the intruded mercury up to a pressure of $500 \mathrm{psi}$.

For the sake of consistency, $P_{\text {inace }}$ is defined as the sum of the specific "closed" void volume and that portion of the specific void volume accessible at pressures higher than 500 psi or having size smaller than $0.3 \mu$. Schematically these are shown in Figure 1 (intruded mercury volume distribution $v s$. pore size) in which $\boldsymbol{P}_{1}$ (or $P_{2}$ ) denotes the starting pressure, $\propto$ designates the pore size separating the two peaks from interand intra-particle pores; and $\beta$ the pore size separating the accessible pores from the inaccessible pores. Ordinarily, the intruded mercury volume does not increase after the $\beta$ point. If it does, it may indicate the presence of consid- 


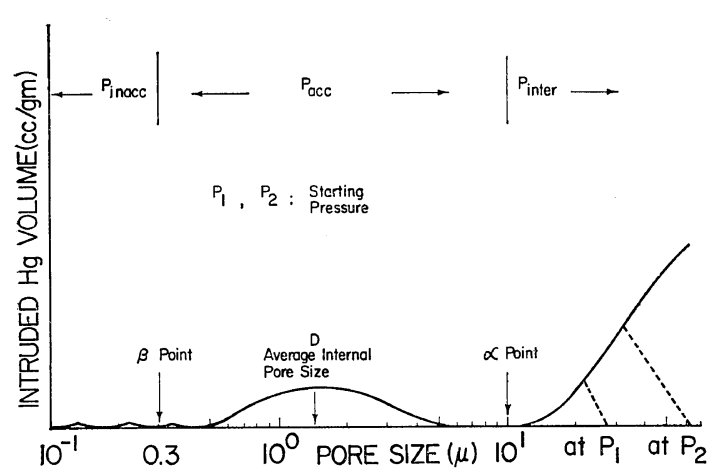

Figure 1. Schematic plot of intruded mercury volume $v s$. pore size showing the definition of porosities in PVC particles.

erable amount of open pores smaller than $0.3 \mu$, cell wall rupture, or shrinkage of solid volume under high pressure.

Thorough vacuum drying of the sample is essential since volatile impurities in the sample often introduce erratic porosity results as revealed by comparing the results before and after vacuum drying of the same sample (see Table III). It appears that undried samples are very susceptible to repacking during the process of mercury intrusion. For samples of very small particle size, longer time for equilibrium intrusion of mercury must be allowed. The system must be able to maintain a vacuum of $1 \mu$ or better. The sample size in the penetrometer should be as large as possible. With the forementioned precautions taken into consideration, the porosity results so determined, were found to be very reproducible within 10\%. The data are interpretted as follows:

Using the pycnometric method as described in "form II" in the instruction manual of
Aminco-Winslow porosimeter cat. No. 5-7106, one can evaluate the portion of $\boldsymbol{P}_{\text {inter }}$ which has pore size greater than the equivalent size at the starting pressure for filling the penetrometer. The sum of this portion of void volume and the intruded mercury volume from the starting pressure to the $\propto$ point (see Figure 1) equals $P_{\text {inter. }}$. The intruded mercury volume between $\propto$ and $\beta$ points in Figure 1 is $\boldsymbol{P}_{\text {acc }}$. From the total porosity, $\left(\boldsymbol{P}_{\text {inter }}+\boldsymbol{P}_{\text {acc }}+\boldsymbol{P}_{\text {inacc }}\right)$, obtained from specific volumes of solid and bulk samples subtracting both $\boldsymbol{P}_{\text {inter }}$ and $\boldsymbol{P}_{\text {acc }}$, gives $\boldsymbol{P}_{\text {in acc }}$. All these three terms, $\boldsymbol{P}_{\text {inter }}, \boldsymbol{P}_{\text {acc }}$, and $P_{\text {inace }}$ are in the dimension of cc/gm, based on unit weight of the polymer. In order to express the porosities in proper dimensions for defining external and internal porosities, they must be expressed in percentage, $V_{\text {inter }} \%$ (cc interparticle voids per unit bulk volume), $V_{\text {acc }}$ $\%$, (cc of accessible intraparticle voids greater than $0.3 \mu$ per unit particle volume), and $V_{\text {inacc }}$, (cc of accessible intraparticle voids smaller than $0.3 \mu$ and inaccessible voids per unit particle volume). The conversion of $\boldsymbol{P}_{\text {inter }}$, $P_{\text {acc }}$, and $P_{\text {inace }}$ to $V_{\text {inter }}, V_{\text {acc }}$, and $V_{\text {inace }}$ requires the specific volumes of the bulk sample and the particle. The latter is obtained from deducting $P_{\text {inter }}$ from specific bulk volume. Let $D$ denote the average accessible intraparticle pore size in $\mu$ and $A_{\text {intra }}$ the total surface area of the accessible intraparticle voids in $\mathrm{m}^{2} / \mathrm{gm}, A_{\text {intra }}$ is equal to,

$$
A_{\text {intra }}\left(\mathrm{m}^{2} / \mathrm{gm}\right)=\frac{6 P_{\mathrm{acc}}}{D}
$$

Results in Table II demonstrate the reproducibility of our porosity data; Table III depicts the porosities of five different resins. The

Table II. Reproducibility of porosity data of a typical PVC Pearls ${ }^{\mathrm{R}}$ from mercury porosimetry ${ }^{\mathrm{a}}$

\begin{tabular}{cccccccc}
\hline Run no. & $\begin{array}{c}\text { Starting } \\
\text { pressure, } \\
\text { psi }\end{array}$ & $\begin{array}{c}P_{\text {inter, }}, \\
\text { cc/gm }\end{array}$ & $\begin{array}{c}P_{\text {acc }}, \\
\text { cc/gm }\end{array}$ & $\%, V_{\text {inter }}$ & $\%, V_{\text {acc }}$ & $D, \mu$ & $A, \mathrm{~m}^{2} / \mathrm{gm}$ \\
\hline 1 & 2.71 & 1.087 & 0.2417 & 53.6 & 26.3 & 1.5 & 1.2 \\
2 & 2.71 & 1.071 & 0.2642 & 52.8 & 27.6 & 1.5 & 1.3 \\
3 & 2.71 & 1.081 & 0.2546 & 53.3 & 26.9 & 1.5 & 1.3 \\
4 & 2.71 & 1.109 & 0.2513 & 54.6 & 27.3 & 1.5 & 1.3 \\
5 & 6.4 & 1.085 & 0.2496 & 53.5 & 26.4 & 1.5 & 1.3 \\
6 & 10.5 & 1.094 & 0.2575 & 53.9 & 27.5 & 1.5 & 1.3 \\
\hline
\end{tabular}

a The inaccessible intraparticle porosity of the sample, $V_{\text {inacc }} \cong 6 \%$. 


\section{R. K. S. Chan and J. Beale}

Table III. Porosity results from electron-microscopy and mercury porosimetry

\begin{tabular}{|c|c|c|c|c|c|c|c|c|}
\hline Resin & $\begin{array}{l}\text { Surface } \\
\text { porosity } \\
\text { from EM }\end{array}$ & $\begin{array}{l}\text { Bulk } \\
\text { density, } \\
\text { lb/ft } \mathrm{ft}^{3}\end{array}$ & $\begin{array}{l}\text { Median } \\
\text { particle } \\
\text { size, } \mu\end{array}$ & $\begin{array}{l}\text { Average } \\
\text { internal } \\
\text { pore size }\end{array}$ & $\begin{array}{l}V_{\text {intra }}, \% \\
\text { from EM }\end{array}$ & $\begin{array}{l}V_{\text {acc, }} \% \\
\text { from } \\
\text { MP }\end{array}$ & $\underset{\%}{V_{\text {inter }}}$ & $V_{\text {inacc }}$, \\
\hline $\begin{array}{l}\text { PVC Pearls } \\
\text { Resin A }\end{array}$ & $\begin{array}{l}\text { No peri- } \\
\text { cellular } \\
\text { membrane }\end{array}$ & 36.0 & 220 & 1.5 & $\begin{array}{l}25 \% \text { from two } \\
\text { small particles; } \\
29 \% \text { from two } \\
\text { big particles }\end{array}$ & 26 & 41 & 6 \\
\hline $\begin{array}{c}\text { PVC PearlsR } \\
\text { Resin B }\end{array}$ & " & 30.8 & 180 & 1.5 & - & 25 & 50 & 6 \\
\hline $\begin{array}{l}\text { VCl-VAc } \\
\text { copolymer } \\
\text { PVC Pearls } \\
\text { Resin A }\end{array}$ & $\begin{array}{l}\text { Solid } \\
\text { skin }\end{array}$ & 30.7 & 250 & 1.4 & $\begin{array}{l}20 \% \text { at edges } \\
24 \% \text { at center } \\
\text { of particle }\end{array}$ & 22 & 52 & 5 \\
\hline $\begin{array}{l}\text { VCl-VAc } \\
\text { copolymer } \\
\text { PVC Pearls } \\
\text { Resin B }\end{array}$ & "I & 32.9 & 250 & 2.0 & - & 22 & 50 & 4 \\
\hline $\begin{array}{l}\text { A regular } \\
\text { suspension PVC } \\
\text { resin after vac } \\
\text { drying }\end{array}$ & $\begin{array}{l}\text { Solid } \\
\text { shell }\end{array}$ & 30.1 & 150 & 0.6 & - & 17.5 & 52.5 & 11 \\
\hline $\begin{array}{l}\text { Same suspension } \\
\text { PVC resin with- } \\
\text { out vac drying }\end{array}$ & " & 30.1 & 150 & 0.6 & - & 19 & 65 & -16 \\
\hline
\end{tabular}

Table IV. Accessible intraparticle porosity of fractions of different particle size from two PVC PearlsR

Sample Fraction Size description $\begin{gathered}\text { Bulk } \\ \text { density, } \\ \mathrm{lb} / \mathrm{ft}^{3}\end{gathered}, \begin{gathered}\boldsymbol{P}_{\mathrm{acc}}, \\ \mathrm{cc} / \mathrm{gm}\end{gathered}$

\begin{tabular}{clccc}
\hline A & 1 & 180 & 34.4 & 0.192 \\
A & 2 & On 100 mesh screen & 35.4 & 0.187 \\
A & 3 & $\begin{array}{c}\text { Through 100 mesh } \\
\text { screen }\end{array}$ & 30.1 & 0.220 \\
B & 1 & 180 & 32.7 & 0.227 \\
B & 2 & $\begin{array}{c}\text { On 100 mesh screen } \\
\text { Through 100 mesh }\end{array}$ & 32.8 & 0.227 \\
B & 3 & screen & & 0.244 \\
& & & &
\end{tabular}

good agreement of the values of $V_{\text {acc }}$ and $V_{\text {intra }}$ of two PVC Pearls ${ }^{\mathrm{R}}$ separately obtained from mercury porosimetry, MP, and electron microscopy, EM, results from their open porosity structure where only small pores $<0.3 \mu$ contribute to $V_{\text {inacc }}$. Also, these two techniques give consistent values of $D$, the average intraparticle pore size. If a sample is fractionated by particle size, the porosities of fraction of different particle sizes can be obtained through porosimetry. For example, the distribution of accessible intraparticle porosity with respect to particle size of two pearl resins is shown in
Table IV.

To recapitulate, using electron microscopy as an absolute technique, one can examine the reliability of the porosity results determined by mercury porosimetry. The surface porosity of PVC particles cannot be covered by mercury porosimetry and has to be supplementarily studied by electron microscopy. The values of interparticle porosity, accessible, and inaccessible intraparticle porosities from porosimetry are usually adequate enough to describe the porosity of a PVC power sample.

\section{CONCLUSIONS}

The porosity distributions of PVC resins produced by different processes, (solution, bulk, emulsion, and suspension) have been compared by electron microscopic technique. It is concluded that porosity in PVC particles arises mainly from agglomeration of precipitated polymer particles in the monomer droplets during polymerization. The intraparticle porosity in $\%, V_{\text {intra }}$, is quantitatively measurable by analyzing the $\%$ void areas in the electron-micrographs of the microtomed center sections from particles of different sizes. Interpretation of mercury porosimetric data gives interparticle void volume, $V_{\text {inter }} \%$, 
accessible, and inaccessible intraparticle void volumes, $V_{\text {acc }} \%$ and $V_{\text {inacc }} \%$. In the case of open porosity the value of $V_{\text {acc }} \%$ obtained from porosimetry is in good agreement with the value of $V_{\text {intra }}$ from electron microscopy. The values of average intraparticle pore size, separately obtained from these two techniques are also consistent. Surface porosity can be supplementarily studied by electron microscopic methods. It is believed that these three quantities, $V_{\text {inter }}$, $V_{\text {acc }}$, and $V_{\text {inace }}$ together with the average intraparticle pore size, $D$, are usually adequate enough in describing the porosity of a PVC powder sample.

\section{NOTATIONS}

$V_{\text {intra }} \%$, intraparticle void volume expressed in $\%$ of particle volume.

$A_{\text {void, }}$ void area in an electron-micrograph of the microtomed section in a PVC particle.

$A_{\text {total }}$, total area of the microtomed section of a particle.

$\boldsymbol{P}_{\text {inter }}, \quad$ interparticle porosity of a PVC powder sample in cc/gm.

$\boldsymbol{P}_{\text {acc }}$ accessible intraparticle porosity of pore size greater than $0.3 \mu$ in a PVC powder sample in cc/gm.

$\boldsymbol{P}_{\text {inace }}$ inaccessible intraparticle porosity plus the portion of accessible intraparticle voids which have size smaller than $0.3 \mu$.
$V_{\text {inter }} \%, \boldsymbol{P}_{\text {inter }}$ expressed in $\%$ of total bulk volume of the powder sample.

$V_{\text {acc }} \%, \quad P_{\text {acc }}$ expressed in $\%$ of particle volume.

$V_{\text {inace }} \%, P_{\text {inacc }}$ expressed in $\%$ of particle volume.

$D, \quad$ average diameter of internal pores in $\mu$. $A_{\text {intra }}, \quad$ specific surface area of accessible intraparticle pores $>0.3 \mu \mathrm{m}^{2} / \mathrm{g}$.

Acknowledgements. The authors wish to thank Drs. G. J. Mantell and W. M. Smith for their encouragement and interest in this work, Mr. C. Worman for performing the experimental work and Miss E. Moore for her literature search. We are particularly grateful to Dr. Hans Von Euler of KemaNord Chemicals, Sweden, for his illuminating communications which lead to several corrections during the preparation of our manuscript.

\section{REFERENCES}

1. L. Engle, presented before the Philadelphia Section, Society of Plastics Engineers, Oct. 1963.

2. P. Gluck, Mater. Plast., 5(2), 90 (1968).

3. K. Fukawa, S. Sakanashi, F. Mochizuki, and Y. Yoshide Kogyo Kagaku Zasshi, (J. Chem. Soc., Japan, Chem. Ind. Sect.), 67(11), 1931, (1964).

4. I. B. Kotlyar and A. M. Sheretskii, Plasticheskie Massey, 2, 7. (1965).

5. Air Products and Chemicals, Inc., Technical Brochure "PVC PEARLS," to be published. 